\title{
DESENVOLVIMENTO RADICULAR DE HÍBRIDOS DE MAMONA SUBMETIDOS À ADUBAÇÃO POTÁSSICA
}

\author{
Hugo Alexandre Coelho, Láislla De Gouveia, Edemar Moro, Carlos Alexandre Costa Crusciol \\ Universidade Estadual Paulista - UNESP, Campus Botucatu/SP. E-mail: hugoalexandrecoelho@bol.com.br
}

\section{RESUMO}

A deficiência de potássio no início do ciclo vegetativo afeta o equilíbrio nutricional comprometendo o desenvolvimento das plantas. O objetivo deste trabalho foi avaliar o efeito do potássio no desenvolvimento do sistema radicular e na produção de matéria seca da parte aérea de híbridos de mamona. O experimento foi instalado em esquema fatorial $5 \times 2$ em delineamento inteiramente casualizado, com quatro repetições. Os tratamentos constaram de cinco doses de K: 0, 25, 50, 100 e 200 ppm e de dois híbridos de mamona (Lyra e Savana). Decorrido 45 dias após a emergência, realizou-se a coleta da parte aérea e do sistema radicular das plantas. As avaliações realizadas foram: comprimento, superfície, diâmetro e matéria seca do sistema radicular e da parte aérea. A adubação potássica causou aumento do diâmetro radicular ao hibrido Savana e redução ao Lyra. A produção de matéria seca de raiz e da parte aérea do hibrido Savana diminuiu com doses a partir de 78 e 116 ppm de potássio, respectivamente.

Palavras-chave: nutrição de plantas; potássio; sistema radicular.

\section{ROOT DEVELOPMENT OF HYBRIDS OF CASTOR BEAN SUBJECTED TO POTASSIUM FERTILIZATION}

\begin{abstract}
A deficiency of potassium at the beginning of the season affects the nutritional balance implicating the proper development of plants. The objective of this study was to evaluate the effect of potassium (K) in the root system development and production of dry matter of shoots of hybrid castor. The experiment was a $5 \times 2$ factorial scheme in a completely randomized design with four replications. The treatments consisted of five doses of K: 0, 25, 50, 100 and 200 ppm and two hybrids of castor (Lyra and Savana). After 45 days after emergence, there was a collection of shoot and root system of plants. The evaluations were: length, area, diameter and dry root and shoot. The addition of potassium caused increased root diameter at the hybrid Savana and reduced at the Lyra. The production of root and shoot dry of the hybrid Savana decreased with doses from 78 and 116 ppm of potassium, respectively.
\end{abstract}

Keywords: plant nutrition; potassium; root system. 


\section{INTRODUÇÃO}

Em 2000 houve uma extraordinária recuperação na produção nacional de mamona na ordem de 132,7 mil toneladas em relação a safra de 1999 que foi 25 mil toneladas. Esta elevação ocorreu devido ao aumento do preço internacional do óleo de mamona brasileira, o qual atendeu a qualidade exigida pelo mercado importador que é no mínimo o óleo industrial do tipo 1 , ou seja, aquele obtido no processo de prensagem (SANTOS et al., 2001). Em 2006/2007 a produção nacional foi de 152,3 mil toneladas (CONAB, 2007).

Apesar da mamoneira possuir boa capacidade de adaptação e ser encontrada vegetando desde o Rio Grande do Sul até a Amazônia (BELTRÃO et al., 2007), a cultura necessita de um alto requerimento de nutrientes para obtenção de produtividades elevadas (SEVERINO, 2006). Segundo Nakagawa e Neptune (1971), para cada $200 \mathrm{~kg}$ de baga produzida, a mamoneira exporta $80 \mathrm{~kg}$ de $\mathrm{N} ; 7,85$ $\mathrm{kg}$ de $\mathrm{P} ; 25,6 \mathrm{~kg}$ de $\mathrm{K} ; 8,81 \mathrm{~kg}$ de $\mathrm{Ca}$ e $6 \mathrm{~kg}$ de $\mathrm{Mg}$ e a quantidade de nutrientes absorvidas aos 133 dias após a germinação foi 156; 5,24; 172; 13,6; $12,6 \mathrm{~kg} \mathrm{ha}^{-1}$ de $\mathrm{N}, \mathrm{P}, \mathrm{K}, \mathrm{Ca}$ e $\mathrm{Mg}$, respectivamente.

A disponibilidade de $\mathrm{K}$ no solo e a sua absorção pelas plantas parecem estar relacionadas com a disponibilidade dos cátions divalentes, $\mathrm{Ca}$ e $\mathrm{Mg}$, dominantes do complexo de troca. Ainda assim, a absorção do $\mathrm{K}$ pelas plantas é favorecida em comparação com outras espécies catiônicas sendo, dentre os cátions macronutrientes, o que se apresenta, em geral, em menor e maior concentração no solo e na planta, respectivamente (OLIVEIRA; CARMELLO; MASCARENHAS, 2001).

A importância do potássio para as plantas é devido às suas diversas funções, participando de processos osmóticos, da síntese de proteínas, da abertura e fechamento de estômatos, da permeabilidade da membrana, do controle do $\mathrm{pH}$ e da ativação de cerca de 60 sistemas enzimáticos, destacando-se a ribulose-bisfosfato carboxilase/oxigenase (Rubisco), enzima chave no processo fotossintético (MALAVOLTA; VITTI; OLIVEIRA, 1997), portanto a deficiência pode comprometer a atividade fotossintética das plantas.

O potássio é o segundo nutriente requerido em quantidade pelas espécies vegetais, tem alta mobilidade na planta, em qualquer concentração, seja dentro da célula, no tecido vegetal, no xilema ou no floema. Esse nutriente não é metabolizado na planta e forma ligações com moléculas orgânicas de fácil reversibilidade, além de ser o íon mais abundante nas células vegetais (MARSCHNER, 1995).

$\mathrm{Na}$ cultura do feijoeiro o $\mathrm{K}$ é exigido em quantidades relativamente elevadas. Além disso, a quase totalidade do $\mathrm{K}$ é absorvida pelo feijoeiro até 40-50 dias após a emergência. Esses são fatores que indicariam alto potencial de resposta ao K aplicado (ROSOLEM, 1996).

$\mathrm{Na}$ cultura do milho, devido a demanda, a taxa de absorção de $K$ pelas raízes é normalmente muito mais alta do que a do $\mathrm{Mg}$. A interface solo-raiz, dessa forma, é mais rapidamente exaurida de potássio do que de magnésio e, assim, à medida que a concentração do $\mathrm{K}$ decresce, o influxo do $\mathrm{Mg}$ aumenta (FONSECA ; MEURER, 1997). A exaustão do K acarreta desbalanço nutricional, afetando tanto 0 sistema radicular como a parte aérea da planta.

Entretanto, o efeito negativo do desbalanço de nutrientes somente é detectado a partir do florescimento, através da determinação do acúmulo de nutrientes e produção de matéria seca. A correção do problema nesse estádio não surtirá mais efeito (ANDREOTTI, 2001).

$\mathrm{O}$ suprimento adequado de $\mathrm{K}$ é importante desde o início do ciclo vegetativo das culturas. Portanto, o objetivo deste trabalho foi 
avaliar $\mathrm{o}$ efeito de diferentes doses de $\mathrm{K}$ no desenvolvimento do sistema radicular de híbridos de mamona.

\section{MATERIAL E MÉTODOS}

O experimento foi conduzido em casa de vegetação no Departamento de Agricultura e Melhoramento Vegetal da Faculdade de Ciências Agronômicas - UNESP, Campus de Botucatu-SP, durante os meses de julho e agosto de 2006.

O solo utilizado apresentou as seguintes características: $\mathrm{pH}$ em $\mathrm{CaCl}_{2}$ de 4,1 ; $\mathrm{P}$ (resina) 8

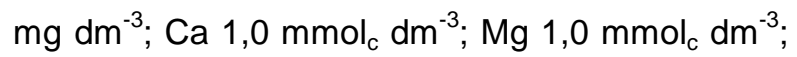
$\mathrm{K} 0,1 \mathrm{mmol}_{\mathrm{c}} \mathrm{dm}^{-3}, \mathrm{Al}^{3+} 15 \mathrm{mmol}_{\mathrm{c}} \mathrm{dm}^{-3}, \mathrm{H}+\mathrm{Al} 67$ $\mathrm{mmol}_{\mathrm{c}} \mathrm{dm}^{-3}$ e saturação por bases $3 \%$.

Após o peneiramento do solo efetuou-se a calagem do solo com calcário dolomítico PRNT $90 \%$ para elevar a saturação por bases a $70 \%$. Em seguida o solo foi incubado com umidade de 80 \% da capacidade de retenção de água, por um período de 30 dias. Após esse período o solo foi dividido em cinco porções. Cada porção recebeu as seguintes doses de K: 0, 25, 50, 100 e 200 ppm. A fonte de $\mathrm{K}$ utilizada foi o cloreto de potássio. Em todas as porções de solo foi realizada adubação complementar com N (50 mg $\mathrm{dm}^{-3}$, fonte uréia) e $\mathrm{P}\left(150 \mathrm{mg} \mathrm{dm}^{-3}\right.$, fonte super fosfato triplo).

O experimento foi instalado em esquema fatorial $5 \times 2$ em delineamento inteiramente casualizado, com quatro repetições. Os tratamentos constaram de cinco doses de $\mathrm{K}$ (descritos acima) e dois híbridos de mamona (Lyra e Savana). A unidade experimental foi constituída por um vaso com 13 litros de solo.

Utilizou-se o híbrido Savana por ser uma cultivar precoce e a Lyra por ter maior percentagem (90\%) de plantas femininas (RANGEL et al., 2003; CHITARRA et al., 2004). Segundo Savy Filho (2005), o percentual de plantas femininas é um fato diretamente relacionado à produtividade.
Após a distribuição dos tratamentos de acordo com o arranjo proposto, os vasos foram irrigados à $80 \%$ da capacidade de retenção de água e em seguida efetuou-se a semeadura. Foram alocadas cinco sementes por vaso. Após a emergência, foi realizado desbaste, mantendo-se duas plantas.

Decorrido 45 dias após a emergência, realizou-se a coleta da parte aérea e do sistema radicular das plantas. As avaliações realizadas foram: comprimento, superfície, diâmetro e matéria seca do sistema radicular e matéria seca da parte aérea.

Para as determinações de comprimento, superfície e diâmetro, retirou-se uma porção representativa da raiz a qual foi digitalizada em "scanner" de leitura ótica, e analisadas pelo programa "Win Mac Rhizo", versão 3.8-b (Regente Instrument Inc., Quebec-Canadá). Depois de digitalizadas as raízes foram secas em estufa $60^{\circ} \mathrm{C}$ por $48 \mathrm{~h}$ para determinação da matéria seca juntamente com o restante do sistema radicular.

Os dados obtidos foram submetidos à análise de regressão, ajustando-se as equações a partir das doses de $\mathrm{K}$ por meio do programa de estatístico SISVAR. Adotaram-se os modelos que foram significativos a $5 \%$ pelo teste de $\mathrm{F}$.

\section{RESULTADOS E DISCUSSÃO}

\section{Comprimento radicular}

O comprimento radicular não foi influenciado pelas doses de $K$ (Figura 1A). Também não houve diferença significativa para a interação dose de $\mathrm{K} \times$ híbrido. Observou-se apenas diferença entre os híbridos, sendo que o Savana apresentou maior comprimento radicular, média de 891,31 m enquanto que o comprimento médio do híbrido Lyra foi de $560,74 \mathrm{~m}$ vaso $^{-1}$. O maior valor do híbrido Savana para este parâmetro pode ser atribuído a seu rápido desenvolvimento inicial. 

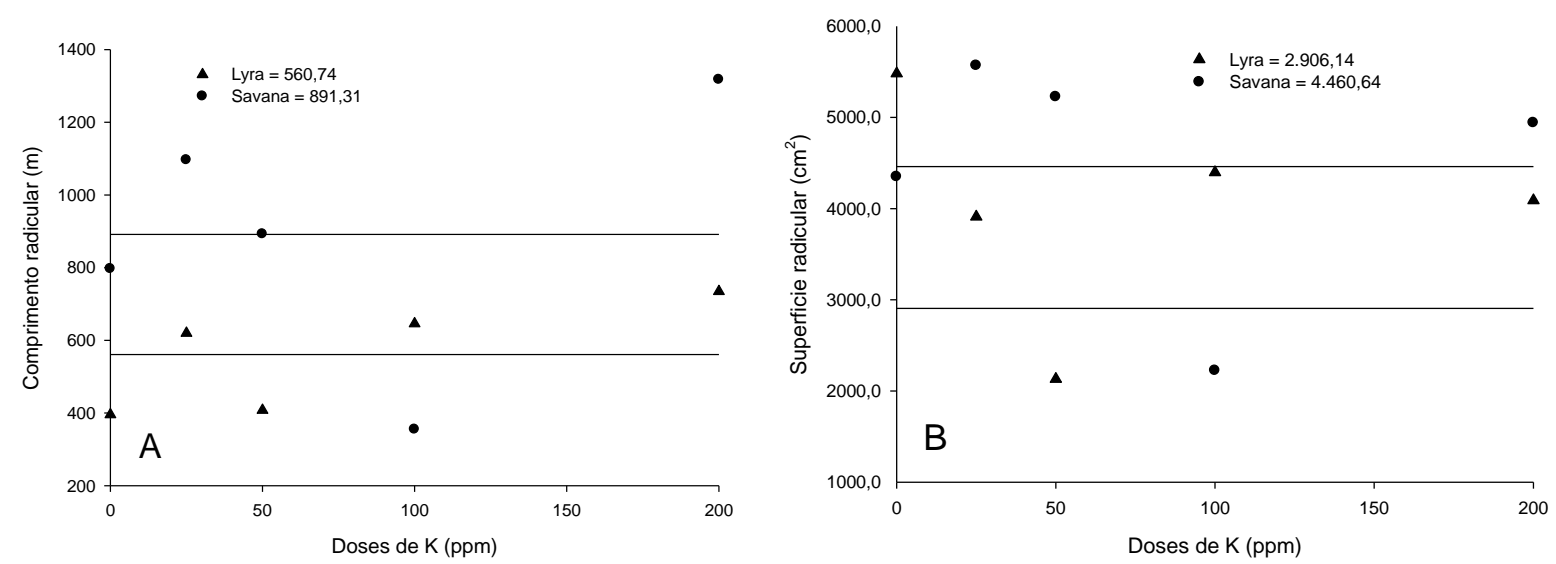

Figura 1. Comprimento radicular (A) e Superfície radicular (B) dos híbridos de mamona Lyra e Savana em função da adubação potássica.

\section{Superfície radicular}

Não houve diferenças para este

parâmetro entre os híbridos avaliados (Tabela 1)

e também para as doses de potássio (Figura 1B).

Tabela 1. Valores de $\mathrm{F}$ para os parâmetros de raiz e matéria seca da parte aérea para os híbridos de mamona Lyra e Savana em função da adubação potássica.

\begin{tabular}{lcccc}
\hline Parâmetro avaliado & $\mathrm{K} \%$ & Híbridos & $\mathrm{K} \times \mathrm{H}$ & $\mathrm{CV} \%$ \\
\hline Comprimento radicular $(\mathrm{m})$ & $\mathrm{ns}$ & $*$ & $\mathrm{~ns}$ & 54,32 \\
Superfície radicular $\left(\mathrm{cm}^{2}\right)$ & $\mathrm{ns}$ & $\mathrm{ns}$ & $*$ & 41,48 \\
Diâmetro radicular $(\mathrm{mm})$ & $*$ & $\mathrm{~ns}$ & $* *$ & 9,27 \\
Matéria seca de raiz $\left(\mathrm{g}\right.$ vaso $\left.{ }^{-1}\right)$ & $*$ & $* *$ & $\mathrm{~ns}$ & 13,64 \\
Matéria seca da parte aérea $^{*} \mathrm{~g}$ & $* *$ & $\mathrm{~ns}$ & $\mathrm{~ns}$ & 9,97 \\
vaso $^{-1}$ ) & & & \\
${ }^{*, * *}, \mathrm{~ns}=$ significativo a 5\% e 1\% de probabilidade e não significativo, respectivamente &
\end{tabular}

\section{Diâmetro radicular}

As dose de $\mathrm{K}$ influenciaram de forma contrária o diâmetro radicular dos híbridos (Figura 2). Com o aumento da adubação potássica 0 híbrido Lyra reduziu o diâmetro radicular, enquanto que o Savana aumentou. $\mathrm{O}$ aumento do $\mathrm{K}$ disponível no solo intensifica $\mathrm{O}$ efeito competitivo sobre a absorção do $\mathrm{Ca}$ e do $\mathrm{Mg}$, sendo mais efetivo sobre esse último. Este efeito de competição à medida que se elevou a adubação potássica pode ter ocorrido para o híbrido Lyra, resultando na redução do diâmetro radicular. O híbrido Lyra parece ser mais sensível à inibição competitiva entre $\mathrm{K}, \mathrm{Ca}$ e Mg. 


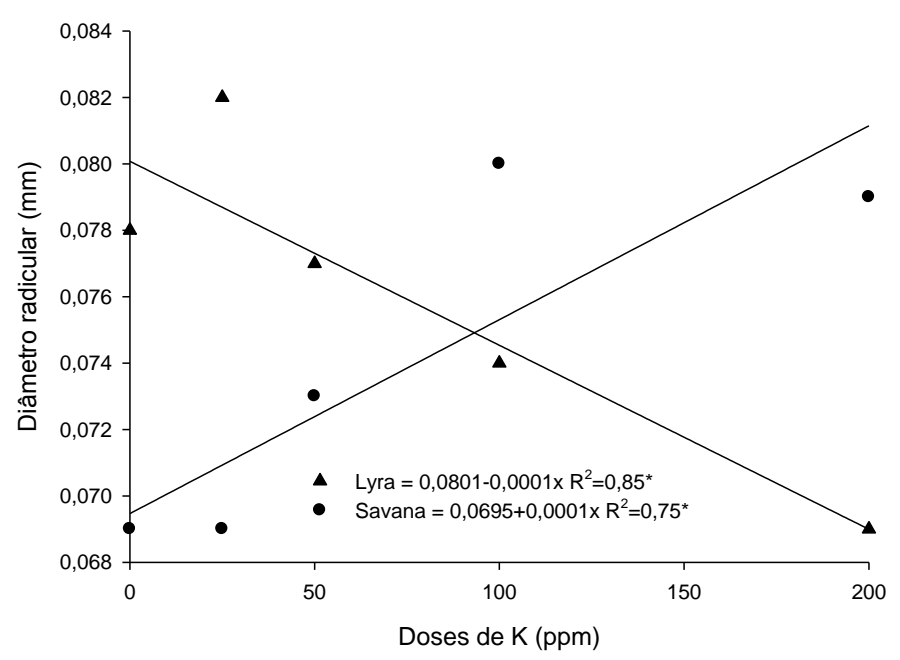

Figura 2. Diâmetro radicular dos híbridos de mamona Lyra e Savana em função da adubação potássica.

\section{Matéria seca radicular}

Os híbridos de mamona apresentaram diferenças significativas em relação à matéria seca do sistema radicular (Tabela 1). $O$ efeito das doses de potássio sobre este parâmetro foi apresentado na Figura 3. O híbrido Lyra não teve a matéria seca afetada pela adubação potássica. Os dados para o híbrido Savana se ajustaram a função quadrática atingindo o máximo de matéria seca $\left(10,42 \mathrm{~g}\right.$ vaso $\left.^{-1}\right)$ com a dose ajustada de 78,5 ppm de K (Figuras 1A e 1B).

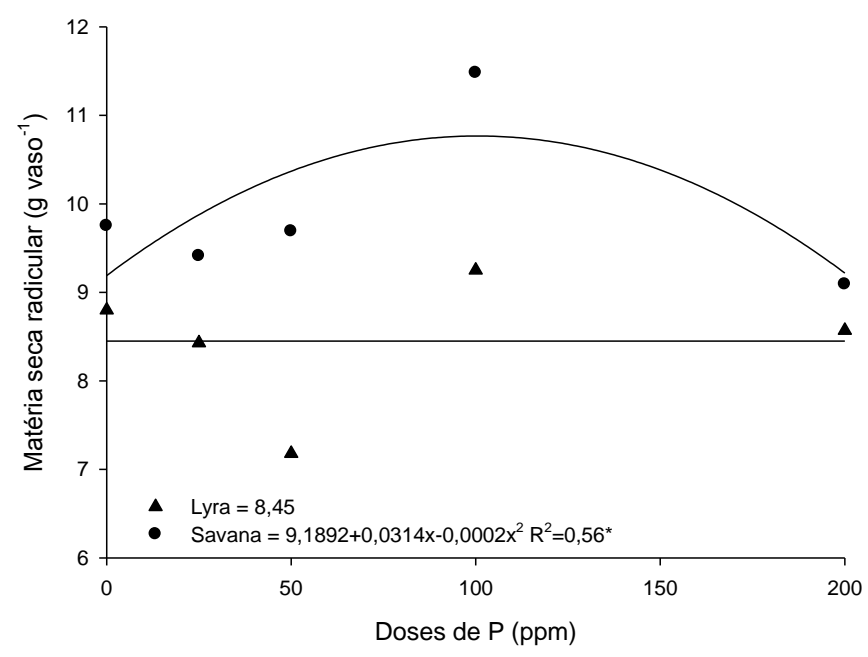

Figura 3. Matéria seca radicular dos híbridos de mamona Lyra e Savana em função da adubação potássica.

Matéria seca da parte aérea

Os híbridos de mamona não apresentaram diferença significativa em relação a matéria seca da parte aérea (Tabela 1). Quanto ao efeito da adubação potássica (Figura 4) os dados para o híbrido Lyra se ajustaram a função linear. Para o tratamento testemunha a produção de matéria seca ajustada pela equação foi de $21,59 \mathrm{~g}$ e com a maior dose de $\mathrm{K}$ (200 ppm) aumentou para $27,13 \mathrm{~g}$ vaso $^{-1}$. $\mathrm{O}$ acréscimo neste 
caso foi de $20 \%$. Em relação ao híbrido Savana os dados foram ajustados a função quadrática. Neste caso a maior produção de matéria seca da parte aérea $\left(28 \mathrm{~g} \mathrm{vaso}^{-1}\right)$ ocorreu com a dose ajustada de 116 ppm de K.

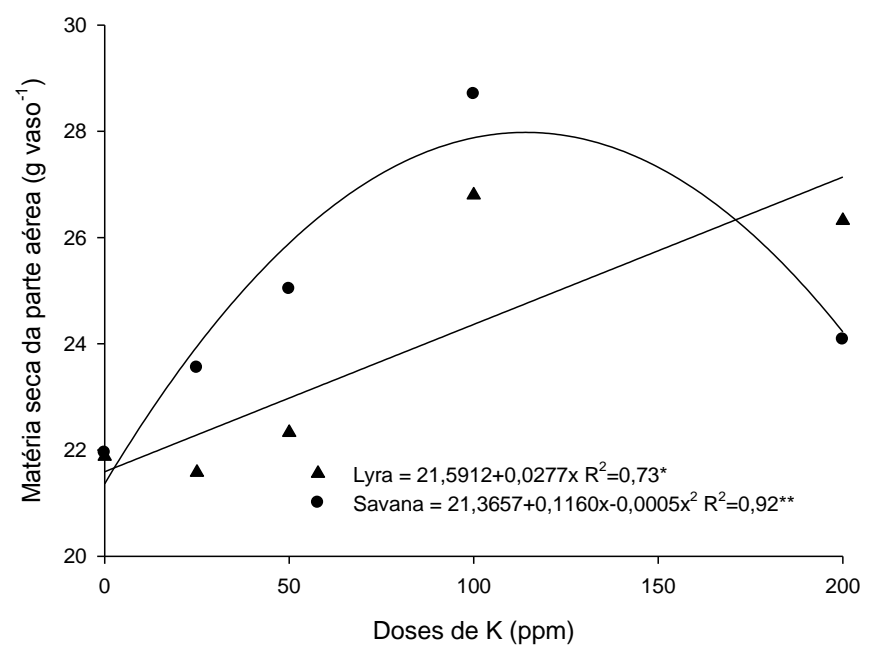

Figura 4. Matéria seca da parte aérea dos híbridos de mamona Lyra e Savana em função da adubação potássica.

Os maiores efeitos da adubação potássica foram observadas no diâmetro radicular e na matéria seca do sistema radicular da mamoneira. Com o aumento da adubação potássica o híbrido Lyra reduziu o diâmetro radicular, enquanto que o Savana aumentou (Figura 2). O aumento do $\mathrm{K}$ disponível no solo intensifica o efeito competitivo sobre a absorção do Ca e do Mg, uma vez que, durante o processo de absorção radicular, estes nutrientes utilizaram os mesmos sítios carregadores (MALAVOLTA; VITTI; OLIVEIRA, 1997). Portanto, a alteração diferenciada no diâmetro entre os híbridos pode ter sido decorrente da sensibilidade de cada material ao desbalanço catiônico na planta.

Quanto a matéria seca radicular o efeito quadrático para o híbrido Savana deve-se ao aumento do diâmetro das raízes. No entanto, a matéria seca aumentou até a dose ajustada de 78 ppm de potássio (Figura 3). A partir dessa dose provavelmente ocorreu competição com outros nutrientes, conforme sugerido para as alterações no diâmetro das raízes.

Os dados de matéria seca da parte aérea também tiveram ajuste quadrático para o híbrido Savana, neste caso, a matéria seca decresceu a partir da dose ajustada de 116 ppm de potássio (Figura 4). A queda da matéria seca da parte aérea a partir da dose supracitada leva a inferir que o híbrido Savana é mais sensível aos problemas decorrentes da competição do potássio com outros cátions.

Analisando-se os dados do híbrido Lyra observou-se efeito linear na produção de matéria seca da parte aérea com as doses aplicadas (Figura 4). Lavres Junior et al. (2005) observaram que o teor de Mg na folha da mamoneira (híbrido Íris) foi maior quando ocorreu deficiência de $\mathrm{K}$, portanto o baixo teor de $\mathrm{K}$ favoreceu a absorção de $\mathrm{Mg}$ provocando desequilíbrio nutricional, afetando a produção de matéria seca de folha do híbrido Lyra. 
Por outro lado, o excesso de potássio associado à deficiência de outros nutrientes pode levar ao engrossamento das raízes, como observado no híbrido Savana (Figura 2). Isto resulta em menor absorção de água e nutrientes e como conseqüência menor desenvolvimento das plantas, conforme pode ser observado para 0 híbrido Savana a partir da dose ajustada de 116 ppm de potássio (Figura 4). Isso ocorre devido a competição desse elemento com os íons cálcio e magnésio pelos sítios de absorção, desbalanço nutricional e dificuldade de absorção de água (MARSCHNER, 1995).

\section{CONCLUSÕES}

A adubação potássica proporcionou aumento do diâmetro radicular ao hibrido Savana e redução ao Lyra.

A produção de matéria seca de raiz e da parte aérea do hibrido Savana diminuiu com doses a partir de 78 e 116 ppm, respectivamente.

\section{REFERÊNCIAS}

ANDREOTTI, M.; RODRIGUES, J.D.; CRUSCIOL, C.A.C.; SOUZA, E.C.A.; CRUSCIOL, C.A.C.; BÜLL, L.T. Crescimento do milho em função da saturação por bases e da adubação potássica. Scientia Agricola, v.58, n.1, p.145150, 2001.

BELTRÃO, N.E.M.; AMORIN NETO, M.S.; ARAÚJO, A.E. Clima e solo. In: AZEVEDO, D.M.P ; BELTRÃO, N.E.M. (Eds). O agronegócio da mamona no Brasil. 2 ed. Brasília: EMBRAPA Algodão, 2007. p. 73-93. Informações Tecnológicas.

CHITARRA, L. G.; MENDES, M.C.; ALMEIDA, V.M.; SILVA, J.S.; MACHADO, F.T.; NETO, J. R. V.; BONFONI. J. Competição de cultivares de mamona em Mato Grosso. In: Congresso Brasileiro de mamona, 2004, Campina Grande,
PB. Anais. Campina Grande: EMBRAPA, 2004. 1 CD - ROM.

COMPANHIA NACIONAL DO ABASTECIMENTO - CONAB. Indicadores da agropecuária. Ano XVI, n. $3.2007 . \quad$ Disponível em http://www.conab.gov.br/conabweb/download/indic adores/ia.mar.2007 acesso em 17 de abril de 2007.

FONSECA, J.A.; MEURER, E.J. Inibição da absorção de magnésio pelo potássio em plântulas de milho em solução nutritiva. Revista Brasileira de Ciência do Solo, v. 21, n.1, p.47-50, 1997.

LAVRES JUNIOR, J.; BOARETTO, R.M.; SILVA, M.L.S.; CORREIA, D.; CABRAL, C.P.; MALAVOLTA, E. Deficiências de macronutrientes no estado nutricional da mamoneira cultivar íris. Pesquisa Agropecuária Brasileira, v. 40, n. 2, p.145-151, 2005.

MALAVOLTA, E.; VITTI, G.C.; OLIVEIRA, S.A. Avaliação do estado nutricional das plantas: princípios e aplicações. Piracicaba: POTAFÓS, 1997. 319p.

MARSCHNER, H. Mineral nutrition of higher plants. London: Academic Press, 1995. 889p.

NAKAGAWA, J.; NEPTUNE, A.M.L. Marcha de absorção de nitrogênio, fósforo, potássio, cálcio e magnésio na cultura da mamoneira (Ricinus Communis L.) cultivar campinas. Anais da Escola Superior de Agricultura Luiz de Queiroz, Piracicaba, v.28, p. 323-327, 1971.

OLIVEIRA, F.A.; CARMELLO, Q.A.C.; MASCARENHAS, H.A.A. Disponibilidade de potássio e suas relações com cálcio e magnésio em soja cultivada em casa-de-vegetação. Scientia Agrícola, v.58, n.2, p.329-335, 2001.

RANGEL, L. E. P.; FERREIRA, L. G.; ALMEIDA, V. M.; MENEZES, V. L. Mamona: situação atual e perspectiva no Mato Grosso. Campina grande: 
EMBRAPA Algodão, 2003. p. 16 (EMBRAPA Algodão. Documento, 106).

ROSOLEM, C.A. Calagem e adubação mineral. In: ARAUJO, R.S.; RAVA, C.A.; STONE, L.F.; ZIMMERMANN, M.J.O. (Ed.) Cultura do feijoeiro comum no Brasil. Piracicaba: Potafós, 1996. cap.4., p.353-385.

SANTOS, R.F.; BARROS, M.A.L.; MARQUES, F.M.; FIRMINO, PT.; REQUIÃO, L.E.G. Analise econômica. In: AZEVEDO, D.M.P. de; LIMA, E.F. (Ed). O agronegócio da mamona no Brasil. Brasília_DF: Embrapa informações tecnológica, 2001. Cap. 1, p. 17-35.

SAVY FILHO, A. Mamona: tecnologia agrícola. Campinas, SP: EMOPI, 2005. 105 p.

SEVERINO, L.S. ; FERREIRA, G. B.; MORAES, C. R. A.; GONDIM, T. M. S.; FREIRE. A. S. W.; CASTRO, D. A.; CARDOSO, G. D.; BELTRÃO, N. E. de M. Crescimento e produtividade da mamoneira adubada com macronutrientes e micronutrientes. Pesquisa Agropecuária Brasileira, v.41, n.4, p. 563-568, 2006. 